\title{
THE APPLICABILITY OF DIFFERENT ENERGY PERFORMANCE CALCULATION METHODS FOR BUILDING LIFE CYCLE ENVIRONMENTAL OPTIMIZATION
}

\author{
B. $\operatorname{KISS}^{1,{ }^{*},}$ ZS. SZALAY2 \\ ${ }^{1}$ Department of Mechanics Materials and Structures, Budapest University of Technology and Economics, \\ 1111 Budapest, Műegyetem rkp. 3., Hungary \\ ${ }^{2}$ Department of Construction Materials and Technologies, Budapest University of Technology and Economics, \\ 1111 Budapest, Müegyetem rkp. 3., Hungary \\ *E-mail: kiss.benedek@szt.bme.hu
}

\begin{abstract}
Building life cycle assessment is getting more and more attention within the topic of environmental impact caused by the built environment. Although more and more research focus on the embodied impact of buildings, the investigation of the operational energy use still needs attention. The majority of the building stock still does not comply with the nearly zero energy requirements. Also, in case of retrofitting, when most of the embodied impact is already spent on the existing structures (and so immutable), the importance of the operational energy rises. There are several methods to calculate the energy performance of buildings covering the range from simplified seasonal methods to detailed hourly energy simulations. Not only the accuracy of the calculations, but the computational time can be significantly different within the methods. The latter is especially important in case of optimization, when there is limited time to perform one calculation. Our research shows that the use of different calculation techniques can lead to different optima for environmental impacts in case of retrofitting. In this paper we compare these calculation methods with focus on computational time, accuracy and applicability to environmental optimization of buildings. We present the results in a case study of the retrofitting of a middle-sized apartment house in Hungary.
\end{abstract}

Keywords: life cycle assessment, building optimization, environmental performance

\section{Introduction}

The analysis of the environmental impact of buildings has been a hot topic now for several years [1,2]. With the advancement in the energy performance regulations the environmental impact related to the operation of the building is being decreased in case of new buildings [3]. It follows that more and more attention is turning on the embodied energy related to the materials within the building, as well as other stages of the life cycle of buildings, such as construction and end-of-life [4, 5]. Life Cycle Assessment (LCA) is a comprehensive method to analyse the complete environmental impact of a building related to all life cycle stages in a 'cradle to grave' perspective [6]. Nevertheless, as an inevitable prerequisite to an LCA an energy performance calculation has to be performed to quantify the operational energy use.

Existing (already built) buildings represent a significant amount of the built environment and this is true for the near future too [7]. Buildings contribute significantly to the greenhouse gas emissions and energy use of the World. An intervention to an existing building mainly influences the energy performance (energy retrofitting) if an environmental improvement is in focus of the project. Therefore, the energy performance calculation is a key aspect of an LCA in case of existing constructions.

With the recent progress in computational performance improvement, more and more complicated optimization processes are available for a wide audience. Different optimization algorithms have been already applied to building energy [8] and environmental impact [9] assessments. Since a building represents a very complicated system, very high number of parameters are needed to describe the possible variations of a solution (geometry, materials, construction assemblies, etc.). To overcome this issue, usually heuristic methods are applied in the optimization (e.g. evolutionary algorithms.), where not all of the possible solu-

This is an open-access article distributed under the terms of the Creative Commons Attribution-NonCommercial 4.0 International License (https://creativecommons.org/licenses/by-nc/4.0/), which permits unrestricted use, distribution, and reproduction in any medium for non-commercial purposes, provided the original author and source are credited, a link to the CC License is provided, and changes - if any - are indicated. 
tions are assessed, but a high variety of them. In such a method, the number of instances (population size) is a key aspect. The number of possible calculations depends on how much time a single calculation takes. Hence the calculation time is also a key aspect in an optimization process.

In this paper we analyse three different energy performance calculation methods from the aspect of computational time, applicability to LCA and accuracy. We present the results of the calculations on an existing case study building. Additionally, the influence of geometrical parameters (that are in reality immutable) on the energy calculation results are also assessed.

\section{Calculation methods applied in this study}

\subsection{Hungarian national method}

The simplest method is the quasi-steady state seasonal method described in the Hungarian government decree on building energy performance specification (referred later in the text as national method). This method is based on international norms, but several simplifications were introduced. A major simplification is that dynamic parameters in the utilisation of heat gains are not calculated, but the utilisation factors are fixed values for two categories of buildings (lightweight and heavyweight).

\subsection{Heat balance method based on utilization factors}

This quasi-steady state method calculates the energy needs for heating and cooling on the basis of the heat balance of the building zone(s). Dynamic effects are taken into account by empirically determined gain and/or loss utilization factors. Here we use a seasonal method from the MSZ EN ISO 13790 standard (referred later in the text as standard method).

\subsection{Dynamic simulation}

Dynamic simulation can calculate the energy consumption in a transient way in hourly or sub-hourly time steps (referred later in the text as simulation method). Tools that facilitate dynamic simulation need to be validated against internationally accepted protocols.

\section{Adjustment and compatibility of the methods}

The three methods are based on different assumptions; thus, the results are expected to diverge. However, to compare them, the initial presumptions (boundary conditions) have to be compatible. The input parame- ters differ in each method, therefore the external conditions applied in each method (climate, use parameters, calculation options) have to be defined from the same source.

\subsection{Boundary conditions}

The weather (climate) conditions for each method are derived from a weather file for Budapest (Hungary). The weather file serves as direct input to the energy simulation. For both other methods the heating degree days are calculated for each month of the year and then summed for the heating period (from October to April). The total solar radiation (direct and diffuse) falling on the façade is also calculated for each month and summed up over the heating (Oct-Apr) and cooling season (May-Sept) for each cardinal direction. User dependent parameters are based on the national regulation; internal gains are set to constant $5 \mathrm{~W} / \mathrm{m}^{2}$ heated area over the entire year; air change rate is set to $\mathrm{ACH}=0.5$ (air changes per hour) during heating season in all calculations (corresponding to basic infiltration rate). In cooling season $\mathrm{ACH}=9$ is set in the national method, which also incorporates the precooling effect of night ventilation. In the standard method and the simulation $\mathrm{ACH}=3$ is set for air change rate during night (from $11 \mathrm{pm}$ to $7 \mathrm{am}$ ) and $\mathrm{ACH}=0.5$ is set during daytime. Although in the other two methods the cooling season is assumed to be from May to September, the first simulations revealed that there is practically no heating or cooling demand in the first and last month of this period, so consequently a night-time ventilation causes extra (unnecessary) heating demand. Because of this, night-time ventilation is set from June to August in the simulation.

\subsection{Calculation time}

As already mentioned in the introduction, calculation time is a key issue if optimization is performed. Therefore, the three methods are compared in the same environment for computational time. The national and standard methods are implemented in Rhinoceros 3D and Grasshopper using Python components. For the building model and the simulation, the Ladybug\&Honeybee [10] plugin is used, which facilitates EnergyPlus as a simulation engine.

It is expected, that increasing the number of thermal zones in the building model, the calculation time increases, since more equations have to be solved. Although both the standard and the simulation method allows for multizone calculation, in this paper only the energy results for the whole building are assessed. However, with increasing the number of zones, the number of external surfaces is increased 


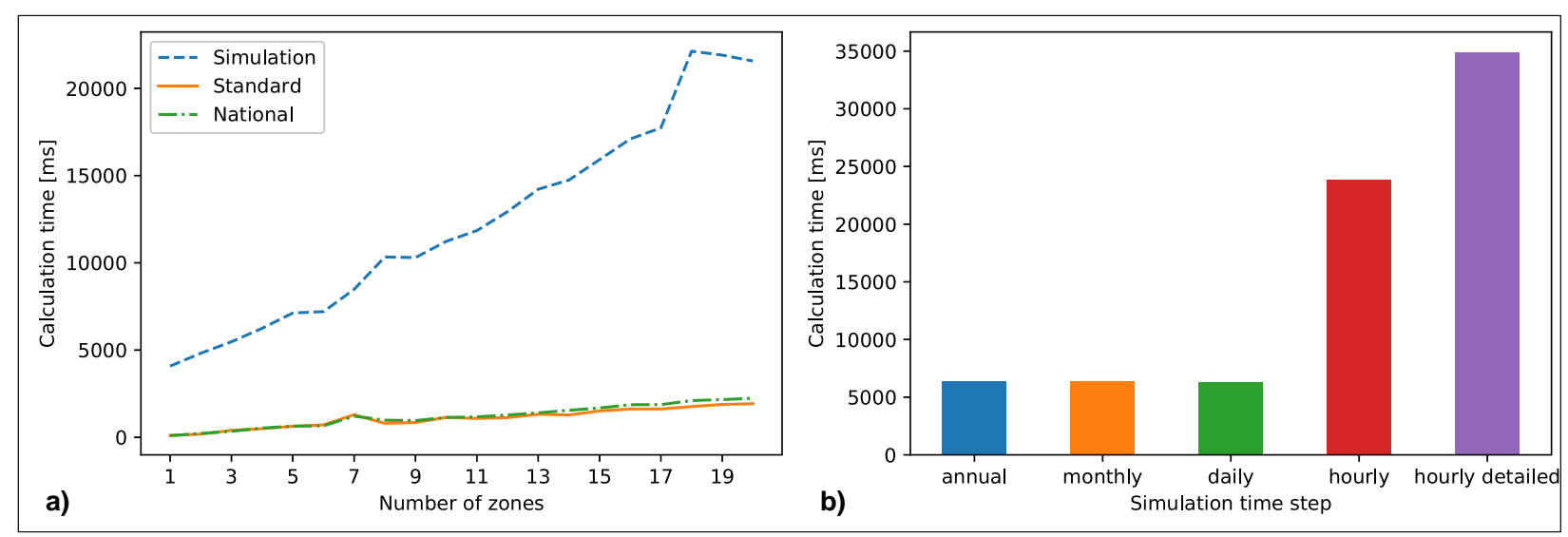

Fig. 1. Calculation time depending on (a) the number of zones and (b) the time step of simulation

as well, that means increasing calculation time for all methods. In Fig. 1a the dependency of the computational time on the number of zones is plotted for each method.

It is expected that the simulation needs much more time than the other two methods, so several simplifications are introduced to this method. In contrast to the default settings, no energy systems sizing calculations are made, since they are out of the scope of this paper. The solar distribution calculation is set to minimal, that means all solar radiation entering the building is falling on the floor. The time step of the simulation within an hour is set from default 6 to 1 . Although the simulations are performed at a minimum resolution of one hour, the processing of the result can be simplified to daily, monthly or annual basis. This postprocessing can take up to $47 \%$ of the calculation time. Figure $1 \mathrm{~b}$ shows the overall calculation time depending on the simulation time step. In Fig. $1 b$ it is also indicated how much reduction in the computational time is achieved with the simpli- fication of the simulation. However, it is still visible in Fig. 1a that after the simplifications the simulation still needs at least ten times so much time for the calculation as the other two methods.

\section{Case study building}

The above described methods are tested on a case study building that was built in the mid-20th century (Fig. 2a). The model of the building is a simplified surface model based on the internal surface areas (Fig. 2b). Each floor is modelled as a separate zone in order to include the thermal storage effect of the internal slabs. The internal walls are modelled as additional thermal mass regardless of their position. For simplification no shading is assumed. The model is generated parametrically, to facilitate optimization. Although the building exists, some geometrical parameters are also defined to assess their effect on the results. The initial parameters of the building as well as the studied bounds are shown in Table 1.

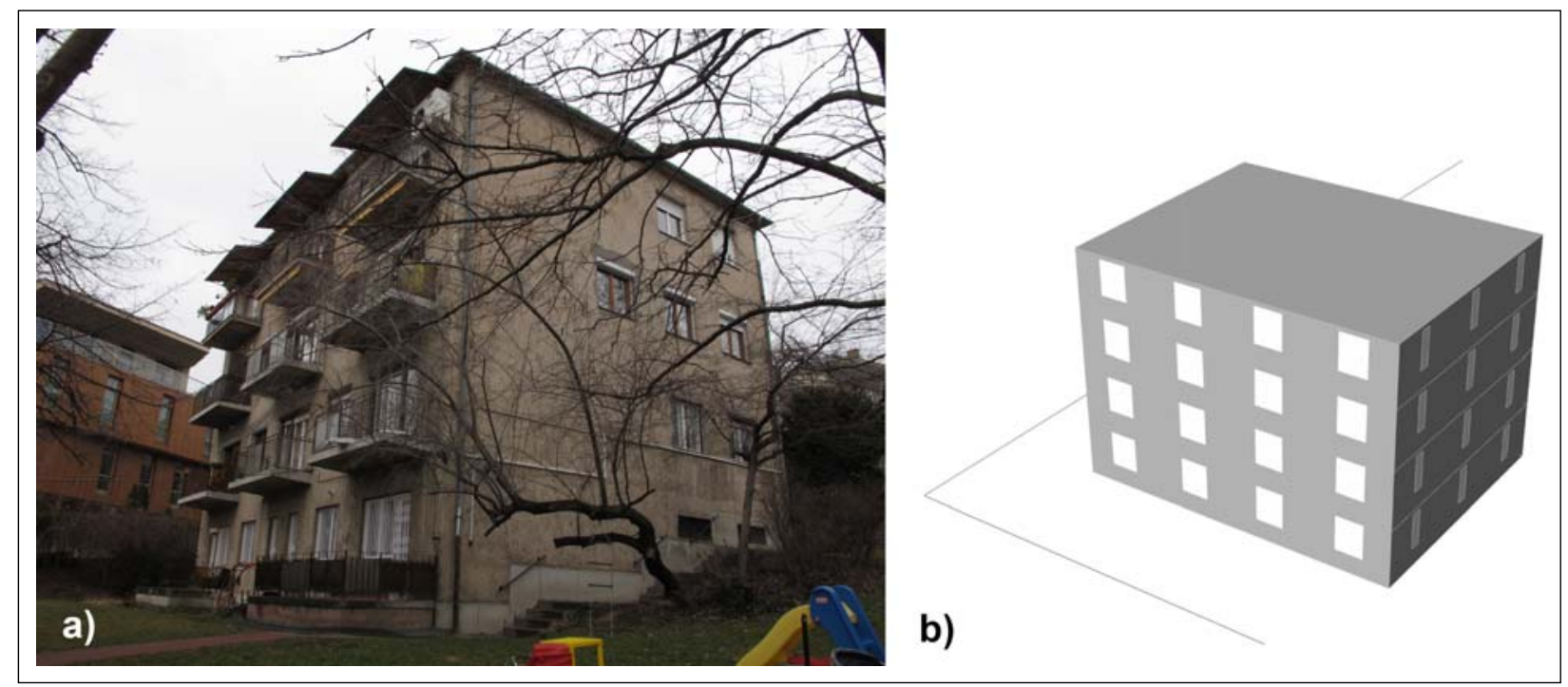

Fig. 2. Photo of the case study building (a) and the simplified model (b) for the calculations 
Table 1. Parameters of the case study building. The values in parentheses are not part of the optimization

\begin{tabular}{lccc}
\hline Parameter & Initial value & Low bound & High bound \\
\hline Heated area per floor & $185 \mathrm{~m}^{2}$ & - & - \\
Number of floors & 4 & $(1)$ & $(20)$ \\
Building length & $12 \mathrm{~m}$ & $5 \mathrm{~m}$ & $30 \mathrm{~m}$ \\
Wall insulation & $5 \mathrm{~cm}$ & $5 \mathrm{~cm}$ & $55 \mathrm{~cm}$ \\
Flat roof insulation & $8 \mathrm{~cm}$ & $8 \mathrm{~cm}$ & $58 \mathrm{~cm}$ \\
Internal wall ratio & $0.4 \mathrm{~m} / \mathrm{m}^{2}$ & $0.0 \mathrm{~m} / \mathrm{m}^{2}$ & $2.0 \mathrm{~m} / \mathrm{m}^{2}$ \\
Window ratio N / W / S E & $0.05 / 0.07 / 0.21 / 0.08$ & $0.01($ all $)$ & $0.6($ all $)$ \\
\hline
\end{tabular}

\section{Results and parameter analysis}

The different parameters of the building are assessed separately. During the evaluation of the effect of a parameter, the other parameters are left on their initial value. For each parameter, the net heating and cooling demand is calculated based on the three methods.

\subsection{Insulation level}

As a first parameter the effect of extra insulation added to the wall and flat roof is assessed.
The insulation on the roof and wall are increased parallelly to improve the whole thermal envelope as one.

Figure 3 shows the dependency of heating and cooling on the added insulation thickness. Evidently the more we increase the insulation thickness, the lower the heating demand is. However, the quantified energy demand differs for each method significantly. It has been showed that the national method typically overestimates the heating demand compared to the standard method [11]. The thickness of the insulation seems to have low impact on the cooling demand,

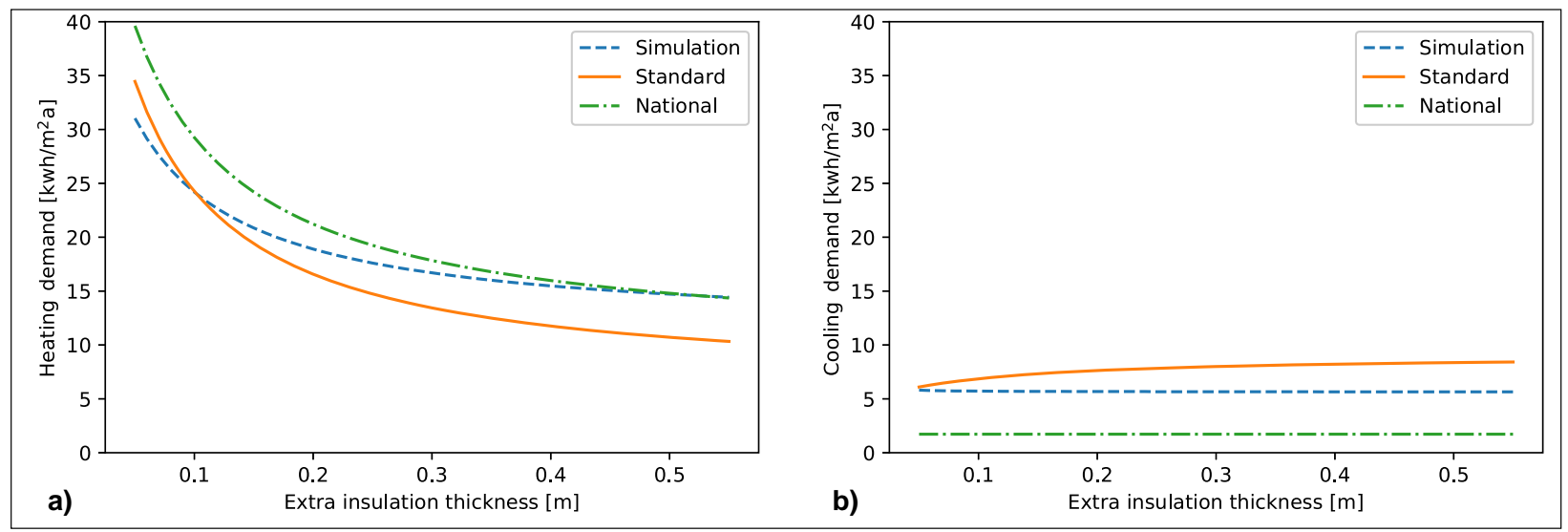

Fig. 3. Calculated heating (a) and cooling (b) demand depending on the added insulation thickness
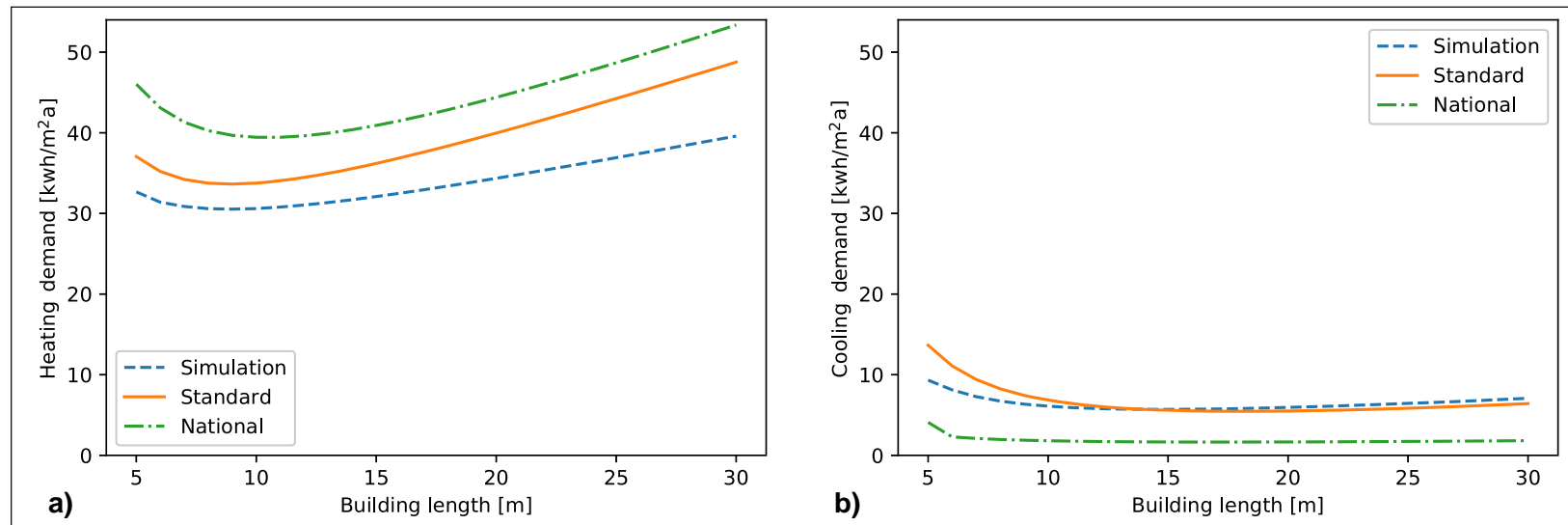

Fig. 4. Calculated heating (a) and cooling (b) demand depending on the aspect ratio of the footprint of the building at low insulation level 
however, the total cooling demand is anyway quite low in this case (because of the low window ratio of the initial model). The standard method is more influenced by the insulation thickness, since the transmission losses are directly incorporated in the formula of the cooling demand.

\subsection{Geometry and window ratio}

Although in an existing building the geometrical parameters are typically immutable, the aspect ratio of the floor plan and the window areas are expected to have high impact on the energy demand which is a key question in case of a new building. Figure 4 shows the dependency of the energy demand on the building length. This length corresponds to the horizontal size of the building parallel to the North-South axis. By changing the aspect ratio not only the exposed surface to heated volume changes but the façade area exposed to South, on which more solar gain can be collected. As expected, the lowest cooling demand is achieved by the almost square floor plan. However, by considering cooling too, the optimum shifts a little bit to a wider south façade. The case is completely dif- ferent when extreme insulation level $(+30 \mathrm{~cm})$ is applied to the building (Fig. 5). Compared to the low-insulated case the heating demand decreases significantly but increase in the cooling demand is only observed in the results of the standard method. Figure 5a shows, that decreasing the building length (which equals to increasing the size of the South façade) results in lower heating demand especially based on the simulation method. It is important to mention here, that neither shadowing from the surrounding environment nor shading of the windows are considered in the model.

To assess the effect of the window ratio, only the glazed surface area of the South façade is changed. Results are shown for both low insulated and high insulated cases. For both cases each method confirms, that increasing the window area results in lower heating demand and higher cooling demand. On the other hand, the assessment of the total demand (sum of heating and cooling) shows very different characteristics depending on the applied method. Figure $6 a$ shows the results for the low insulated case.

For all three methods the total demand is decreased if higher window ratio is used, which is explained by the dominance of heating demand in the

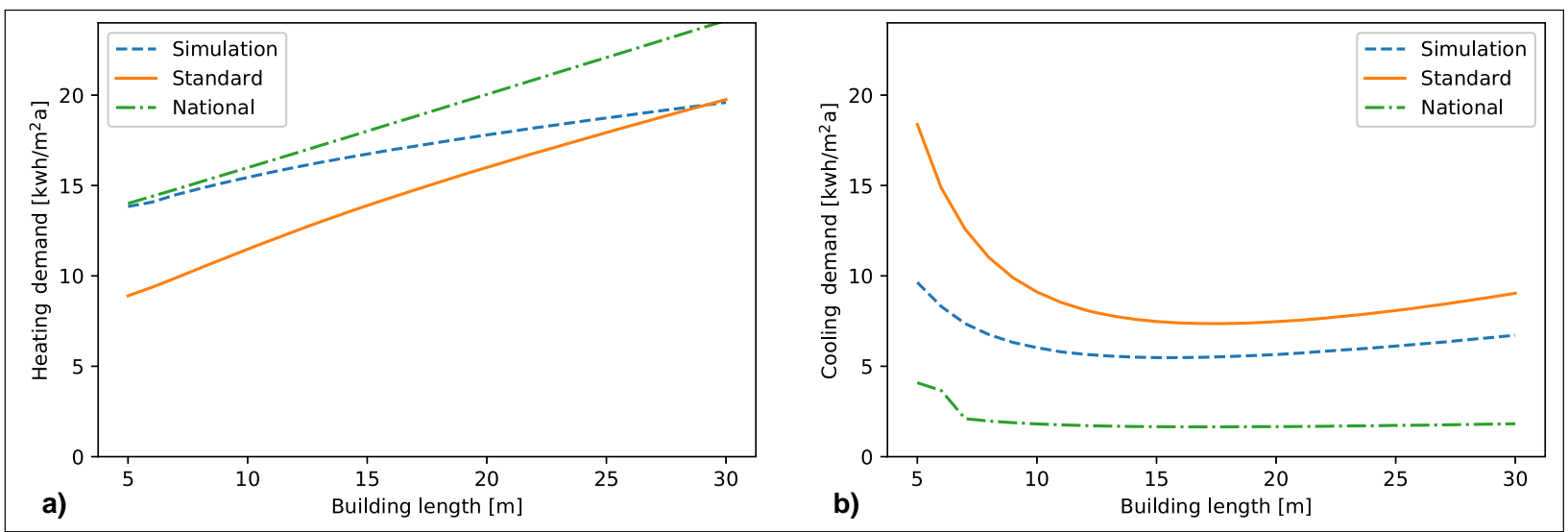

Fig. 5. Calculated heating (a) and cooling (b) demand depending on the aspect ratio of the footprint of the building at extreme insulation level
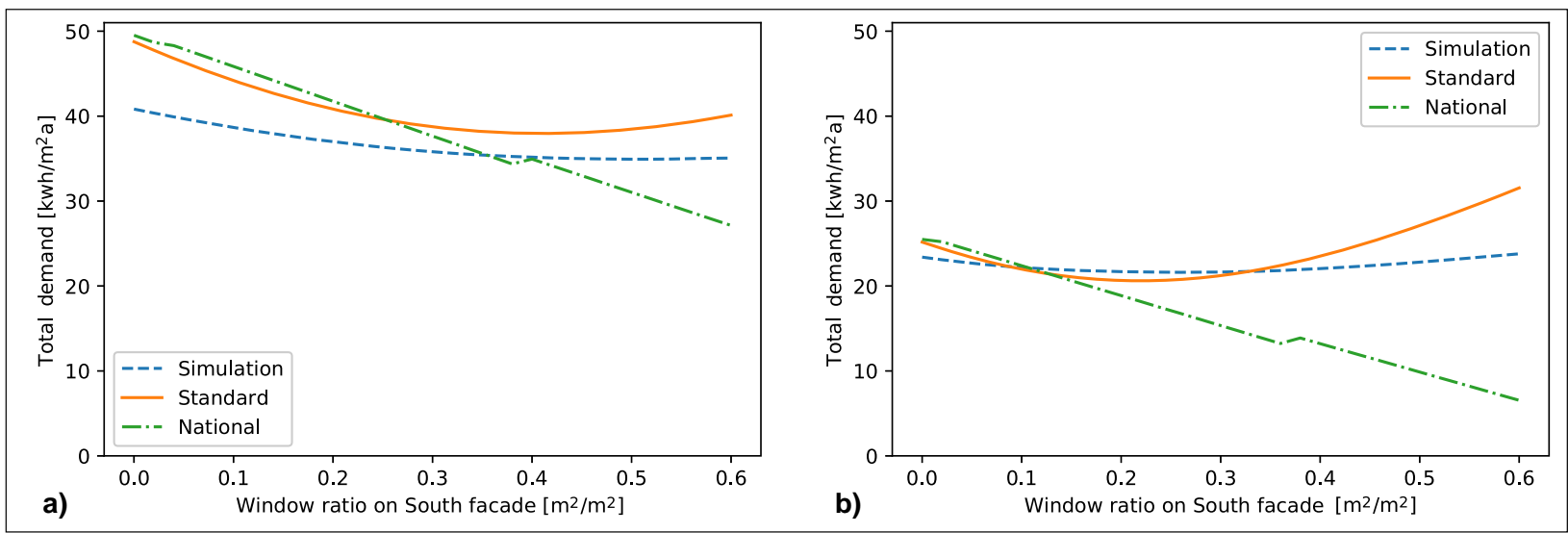

Fig. 6. Calculated total energy demand depending on the window ratio for low-insulated (a) and extreme insulated (b) case 
total. When a high insulation level is applied a significant optimum can be observed for both the standard and the simulation method (Fig. 6b). The national method fails to provide this kind of optimum, which is presumably explained by the inaccuracy of the cooling demand calculation.

\subsection{Optimization}

The parametric definition of the model and the implementation of the three methods in the same environment enables the optimization of the above specified parameters based on each energy calculation method. The optimization is performed with the Octopus plugin [12] of Grasshopper, that implements an evolutionary multi-objective optimization algorithm. The objective of the optimization is the total energy demand. For all three cases the same initial conditions are set. To limit the computational time the population size was set to 10 and the number of generations was limited to 20. Figure 7 shows the development of the solutions over the generations for each energy calculation method. Table 2 indicates the best found solution for each method as well as the elapsed calculation time.

The three methods more or less lead to the same building shape (close to square footprint). The national and the simulation methods both agree on extreme high insulation. The standard method leads to lower insulation level, however, it is still unconventionally high. Contrary to the national method, the other two methods optimize the window ratio to a realistic size. The national method increases the window size continuously, because the cooling demand estimation is very inaccurate in this method. Consequently, the optimization leads to a meaningless solution. In case of the other two methods the optimum is quite close to each other aside from insulation thickness. The standard method performs approximately 5 times faster than the simulation method regarding calculation time. This advantage could be used to increase the population size, which decreases the probability of getting stuck in a local optimum.

\section{Discussion and conclusions}

In this paper we assessed three different building energy demand calculation methods in terms of accuracy, parameter sensitivity and calculation time. Goal of this assessment is to find the trade-off between required accuracy and tolerable calculation time, since the latter aspect plays a key role in an optimization process. The results are presented on an existing case study building and the assessment is further extended to include geometrical parameters as well.

We showed that the calculation method of the Hungarian energy regulation does not provide enough precision in the cooling demand estimation that makes it inapplicable for optimization processes. On the other hand, the building energy simulation-based method needs at least five times so much time to perform the calculations. The method based

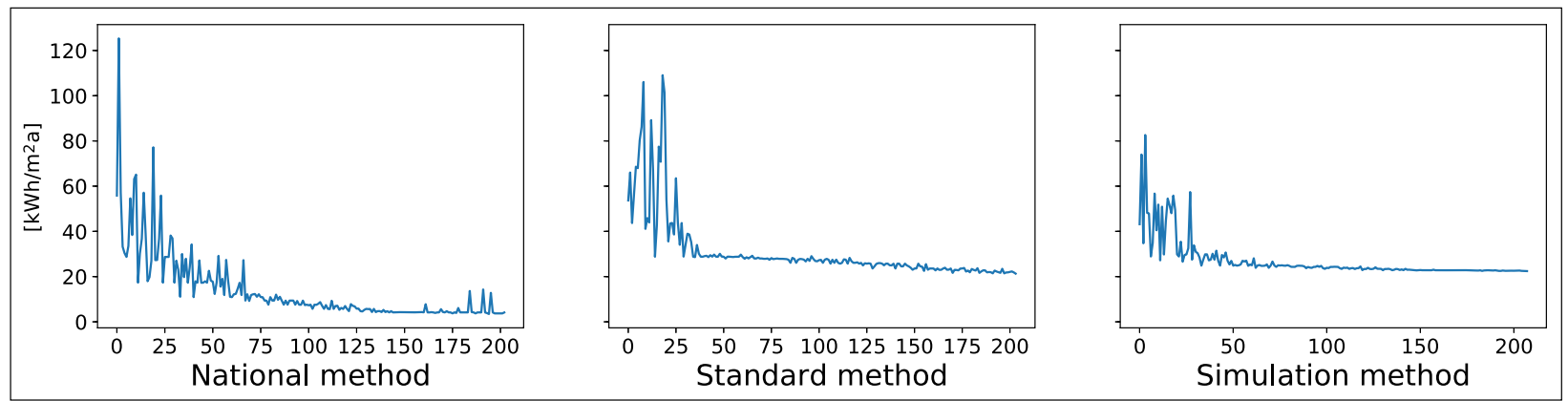

Fig. 7. The evolution of the best solution during optimization for each method

Table 2. Parameters of the optimized building and the calculation time for each method

\begin{tabular}{llll}
\hline Parameter & \multicolumn{1}{c}{ National method } & \multicolumn{1}{c}{ Standard method } & Simulation method \\
\hline Building length & $8 \mathrm{~m}$ & $9 \mathrm{~m}$ & $11 \mathrm{~m}$ \\
Wall insulation & $38 \mathrm{~cm}$ & $17 \mathrm{~cm}$ & $43 \mathrm{~cm}$ \\
Flat roof insulation & $41 \mathrm{~cm}$ & $20 \mathrm{~cm}$ & $46 \mathrm{~cm}$ \\
Internal wall ratio & $0.4 \mathrm{~m}^{2} / \mathrm{m}^{2}$ & $1.4 \mathrm{~m}^{2} / \mathrm{m}^{2}$ & $1.7 \mathrm{~m}^{2} / \mathrm{m}^{2}$ \\
Window ratio N / W / S E & $0.05 / 0.44 / 0.60 / 0.14$ & $0.04 / 0.12 / 0.19 / 0.02$ & $0.13 / 0.03 / 0.21 / 0.19$ \\
Total net energy demand & $3.71 \mathrm{kWh} / \mathrm{m}^{2} \mathrm{a}$ & $21.31 \mathrm{kWh} / \mathrm{m}^{2} \mathrm{a}$ & $22.43 \mathrm{kWh} / \mathrm{m}^{2} \mathrm{a}$ \\
Calculation time & $7 \mathrm{~m} \mathrm{30} \mathrm{s}$ & $6 \mathrm{~m} 21 \mathrm{~s}$ & $33 \mathrm{~m} 58 \mathrm{~s}$ \\
\hline
\end{tabular}


on the MSZ EN ISO 13790 standard seems to provide an appropriate trade-off between reliability and computational time.

\section{Acknowledgements}

The work of Benedek Kiss was supported by the ÚNKP-17-3-I new national excellence program of the Ministry of Human Capacities. We are grateful to the Hungarian Academy of Sciences awarded Zsuzsa Szalay with the János Bólyai Research Scholarship, which supported her work. The research reported in this paper was supported by the BME-Water sciences \& Disaster Prevention FIKP grant of EMMI (BME FIKP-VÍZ).

\section{References}

[1] Sartori I., Hestnes A. G. (2007), Energy use in the life cycle of conventional and low-energy buildings: A review article. Energy Build. 39, 249-57.

[2] Anand C. K., Amor B. (2017), Recent developments, future challenges and new research directions in LCA of buildings: A critical review. Renew Sustain Energy Rev. 67, 408-16.

[3] Blengini G. A., Di Carlo T. (2010), The changing role of life cycle phases, subsystems and materials in the LCA of low energy buildings. Energy Build. 42(6), 869-80.
[4] Szalay Z., Zöld A. (2007), What is missing from the concept of the new European Building Directive? Build Environ. 42(4), 1761-9.

[5] IEA-EBC, Assessment life cycle related environmental impacts caused by buildings, year. Available from: http:// annex72.iea-ebc.org/ (viewed: 2018-06-18)

[6] Moncaster A. M., Symons K. E. (2013), A method and tool for 'cradle to grave' embodied carbon and energy impacts of UK buildings in compliance with the new TC350 standards. Energy Build. 66, 514-23.

[7] King D. (2010), Engineering a Low Carbon Built Environment: The Discipline of Building Engineering Physics. London: Royal Academy of Engineering.

[8] Attia S., Hamdy M., O’Brien W., Carlucci S. (2013), Assessing gaps and needs for integrating building performance optimization tools in net zero energy buildings design. Energy Build. 60, 110-24.

[9] Hollberg A., Ruth J. (2016), LCA in architectural design - a parametric approach. Int. J. Life Cycle Assess. 21(7), 943-60.

[10] Mostapha Sadeghipour Roudsari, Michelle Pak, Smith A. (2013), Ladybug: a parametric environmental plugin for grasshopper to help designers create an environmentally-conscious design. 13th Conf. Int. Build. Perform. Simul. Assoc. 3129-35.

[11] Szalay Zs., Kiss B. (2017), Dinamikus paraméterek az energiaigény számításában 1. rész: Nettó fütési energiaigény avagy szorozzunk-e hasznosítási tényezővel? Magyar Épületgépészet, 9, 20-27.

[12] Vierlinger R. (2013), Multi Objective Design Interface. Master Thesis. TU Wien, pp. 1-61. 